\title{
Rancang Bangun Aplikasi Sistem Peminjaman Unit Multimedia Menggunakan Metode Waterfall
}

\author{
Gugum Gumelar $^{1}$, Ricki Sastra $^{2}$ \\ ${ }_{1,2}^{1,2}$ niversitas Bina Sarana Informatika \\ e-mail: ${ }^{1}$ gugumgumelar587@gmail.com, ${ }^{2}$ ricki.rkt@bsi.ac.id
}

\begin{abstract}
Abstrak - Sistem Peminjaman Unit Multimedia pada suatu instansi merupakan hal yang vital. Dimana setiap instansi akan membutuhkan berbagai item atau inventory lainnya untuk menjalankan dan mendorong event tersebut berjalan. Barang-barang multimedia yang dibutuhkan hanya sesaat dalam suatu acara harus berfungsi dengan baik agar acara dapat berjalan dengan lancar.Selama ini proses peminjaman masih belum optimal, peminjaman masih dilaksanakan secara konvensional dengan pencatatan menggunakan media buku dan memiliki kekurangan karena masih terdapat beberapa kesalahan. Dan dalam proses peminjaman barang masih sering terjadi kesalahan komunikasi antara karyawan dan pemilik dengan pelanggan, mengingat jumlah barang yang dimiliki rumit untuk mengatur ketersediaan unit barang. Selain itu proses pendataan barang multimedia masih menggunakan formulir untuk pengisian data sehingga dapat terjadi kesalahan pencatatan pada saat proses peminjaman. Dengan adanya aplikasi system peminjaman barang yang dirancang menggunakan metode Waterfall. diharapkan dapat mendukung proses input aplikasi barang pegawai, pengadaan barang, pengecekan stok, dan laporan barang masuk sehingga proses dapat berjalan dengan baik.
\end{abstract}

Kata Kunci: Peminjaman,Metode Waterfall,Sistem

Abstract - The Multimedia Unit Loan System in an agency is vital. Where each agency will need various items or other inventory to run and encourage the event to run. Multimedia items that are needed only for a moment in an event must function properly so that the event can run smoothly. So far the lending process is still not optimal, borrowing is still carried out conventionally by recording using book media and has shortcomings because there are still some errors. And in the process of borrowing goods, communication errors often occur between employees and owners with customers, considering the number of goods owned is complicated to regulate the availability of units of goods. In addition, the data collection process for multimedia goods still uses forms to fill in data so that recording errors can occur during the borrowing process. With the application of the goods lending system designed using the Agile method. expected to support the process of inputting employee goods applications, procurement of goods, checking stock, and reports of incoming goods so that the process can run well

Keywords: lending system,Metode Waterfall,,System

\section{PENDAHULUAN}

Sistem peminjaman barang di suatu instansi merupakan sesuatu hal yang vital. Dimana di setiap perusahaan yang bergerak dibidang jasa maka akan memerlukan berbagai barang atau inventaris lainnya untuk menjalankan sekaligus mendorong berjalannya kegiatan. Barang atau inventaris yang telah rusak, using atau keperluan barang harus segera terpenuhi agar kegiatan dapat berjalan dengan lancar.

Oleh karena itu, perusahaan harus berusaha meningkatkan performa sistem sehingga bisa memberikan informasi terbaru yang dibutuhkan pihak pelanggan. Perusahaan sendiri di hadapkan dengan tantangan bagaimana cara mereka melayani para pelanggan dengan cepat tanpa di batasi jarak waktu dan tempat. Karena faktor-faktor yang dapat mempengaruhi seperti lokasi kantor, jam operasional, informasi produk dan kemacetan lalu lintas dapat mempengharui atau bahkan mengurangi jumlah transaksi yang bahkan dapat mengakibatkan pelanggan beralih ke perusahaan yang lebih baik.

Kajian yang dilakukan oleh Kamaruddin menjelaskan pengembangan dan pembangunan sistem informasi penyaluran bantuan Raskin. Sistem informasi ini dapat digunakan sebagai sarana untuk membantu pengelolaan data dan menambah transparansi proses pendistribusian Raskin yang sedang berlangsung. Penelitian ini menggunakan metode kualitatif lapangan dengan strategi desain and creation yaitu selain melakukan penelitian juga melakukan pembuatan sistem menggunakan metode perancangan waterfall (Tone, 2016).

"Perancangan adalah sebuah proses mendefinisikan sesuatu yang dikerjakan dengan menggunakan Teknik yang bervariasi serta melibatkan deskripsi mengenai arsitektur serta detail 
komponen dan juga keterbatasan yang akan dialami dalam proses pengerjaanya" (Septiani et al., 2019).

Khasbi, Nugraha dan Muzid (Khasbi, Nugraha, \& Muzid, 2016) "melakukan penelitian tentang sistem informasi peminjaman barang dan ruangan berbasis website. Pada penelitian tersebut menggunakan metode waterfall dan hasilnya sistem informasi berbasis web lebih mudah dalam proses peminjaman dan serta laporan yang cepat dan Tepat"

Penggunaan sistem manual, masih banyak sekali kekurangan dalam proses pengerjaannya. Dimulai dari salah memasukkan nomor, tanggal, Data yang kurang tersusun dengan rapi, Pemakaian kertas berlebihan, Menyulitkan proses pencarian dokumen barang, Penginputan data yang sama harus diulang. Bila ada orderan baru dan ternyata sama, hanya saja kodenya yang berbeda. Semua itu harus dicari satu persatu atau diketik ulang, Penginputan data customer masih menggunakan sistem manual, Data penginputan sering tidak valid, dan masih sering terjadi kekeliruan dalam pembuatan input data customer, dan memperlambat waktu pengerjaan . Hal ini sangat memakan waktu yang cukup lama dalam pengerjaan. Dan bisa dikatakan kurang efisien.

"Peminjaman adalah suatu aktifitas yang dilakukan oleh konsumen sebelum memesan" (Latest et al., 2018)

Sewa adalah suatu perjanjian dimana yang mempunyai barang (lessor) hak kepada orang yang menyewa (lessee) untuk menggunakan suatu asset selama periode waktu yang disepakati. Sebagai imbalannya, lessee melakukan pembayaran atau serangkaian pembayaraan kepada lessor. Peminjaman barang atau jasa pada event merupakan salah satu aspek yang cukup berkembang, menyadari hal itu setiap perusahaan yang bergerak di bisnis ini berlomba lomba untuk melakukan terobosan masingmasing agar tidak ditinggal oleh pelanggan. Kota Jakarta adalah kota metropolitan yang di kenal begitu banyak gedung-gedung, kantor, balai, hotel dan berbagai tempat lainnya yang dapat digunakan berbagai macam event. "Perancangan sistem adalah Penentuan proses data yang diperlukan oleh sistem baru, jika sistem itu berbasis komputer perancangan dapat dinyatakan spesifikasi peralatan yang digunakan" (Yuliana \& Azizah, 2019).Seperti contoh pernikahan, seminar, rapat, dan pameran yang memerlukan barang atau jasa yang bersifat hanya digunakan dan diperlukan pada saat event sedang berlangsung.

Keterbatasan barang yang dimiliki penyelenggara bisa saja menjadi masalah jika dalam satu event tertentu mereka tidak memilik barang yang diperlukan. Maka dari itu perusahaan penyedia barang dan jasa perlengkapan event menjadi pilihan bagi penyelenggara event itu sendiri untuk memesan barang untuk memperlengkapi kekurangan barang yang dibutuhan dalam event tersebut.

\section{METODE PENELITIAN}

Penelitian ini menggunakan metode kualitatif lapangan dengan strategi desain dan rancangan yaitu selain membuat penelitian juga terdapat proses pembuatan sistem menggunakan metode pengembangan perangkat lunak Agile .Dalam proses pengembangan agile kita mengenal dengan literasi atau perulangan. Singkatnya, jika suatu proyek pengembangan software dikerjakan dengan menggunakan metode Agile, maka selama waktu pengerjaaannya akan selalu dijumpai proses pengembangan yang akan dilakukan berulang. "Metode Agile adalah framework konseptual dengan pendekatan pengembangan yang iterative dan increment" (Listiyoko et al., 2017).

1. Analisa kebutuhan perangkat lunak

Penulis melakukan analisa kebutuhan secara berkala.

2. Merancang

Pada tahap ini, penulis membuat Analisa rancangan menggunakan diagram UML ( diagram Use case, diagram Activity) serta alur yang dibutuhkan untuk membuat desain.

3. Pembuatan Sistem Sesuai dengan Rancangan dan Kebutuhan

Pada tahap ini penulis membuat Sistem Aplikasi Peminjaman Barang untuk perusahaan agar mempermudah kinerja bagian peminjaman.

4. Pengujian

Pengujian dapat dilakukan dengan menggunakan blackbox testing.

\section{Metode Pengumpulan Data}

Teknik pengumpulan data yang digunakan oleh penulis dalam melakukan pengumpulan data untuk pembuatan Tugas Akhir adalah:

1. Pengamatan (Observation)

Penulis melakukan pengumpulan data dengan cara observasi dan mencari penyedia barang atau jasa atau vendor lainnya.

2. Studi Pustaka

Penulis mencari dan mengambil sumber referensi dari buku-buku, jurnal, Internet dan semua referensi yang berhubungan dengan judul yang di bahas.

\section{HASIL DAN PEMBAHASAN}

\section{A. Analisis Kebutuhan}

1. Kebutuhan Owner

a. Proses login sistem harus dapat memvalidasi

b. Proses pengecekan Peminjaman Barang harus memvalidasi 
c. Proses mengelola Peminjaman Barang harus memvalidasi

d. Proses melihat Data Barang harus tervalidasi

2. Kebutuhan Karyawan

a. Proses login harus dapat memvalidasi

b. Proses Menginput Banyaknya Stok Barang dapat tervalidasi

c. Memberi Notif Ada Atau Tidak Barang

d. Proses input Pengeluaran Barang harus tervalidasi

3. Kebutuhan Sistem

a. Owner harus melakukan login terlebih dahulu agar dapat mengelola dengan memasukkkan username dan password.

b. Karyawan harus melakukan login terlebih dahulu agar dapat melihat data ketersediaan barang dan menginput pengeluaran barang.

\section{B. Rancangan Diagram Use Case}

Pada rancangan diagram usecase ini, terdapat 2 aktor. Beberapa actor tersebut ada owner dan karyawan. Pertama, owner dapat mengecek pengiriman barang pada saat customer request barang ke Perusahaan. Kedua, owner dapat mengelola peminjaman barang. Ketiga, owner dapat melihat data barang. Semisalkan digudang kondisi barang ada atau tidak. Lalu karyawan sebagai actor kedua dapat melakukan input banyaknya data barang, melihat notifikasi yang dikirim oleh owner untuk mencari ketersediaan barang di gudang ada atau tidaknya. Jika sudah, karyawan dapat menginput pengeluaran barang tersebut.



Gambar1 Use Case
Deskripsi Diagram UseCase Sistem Peminjaman Barang

\begin{tabular}{|l|l|}
\hline Use Case Name & $\begin{array}{l}\text { Sistem Peminjaman } \\
\text { Barang }\end{array}$ \\
\hline Requirements & $\begin{array}{l}\text { Ownelakukan login. } \\
\text { berhasil login. Karyawan }\end{array}$ \\
\hline Goal & $\begin{array}{l}\text { Owner dan Karyawan } \\
\text { dapat menampilkan } \\
\text { dashboard }\end{array}$ \\
\hline Pre-Conditions
\end{tabular}

\section{Rancangan Diagram Aktivitas}

a. Diagram aktivitas Owner

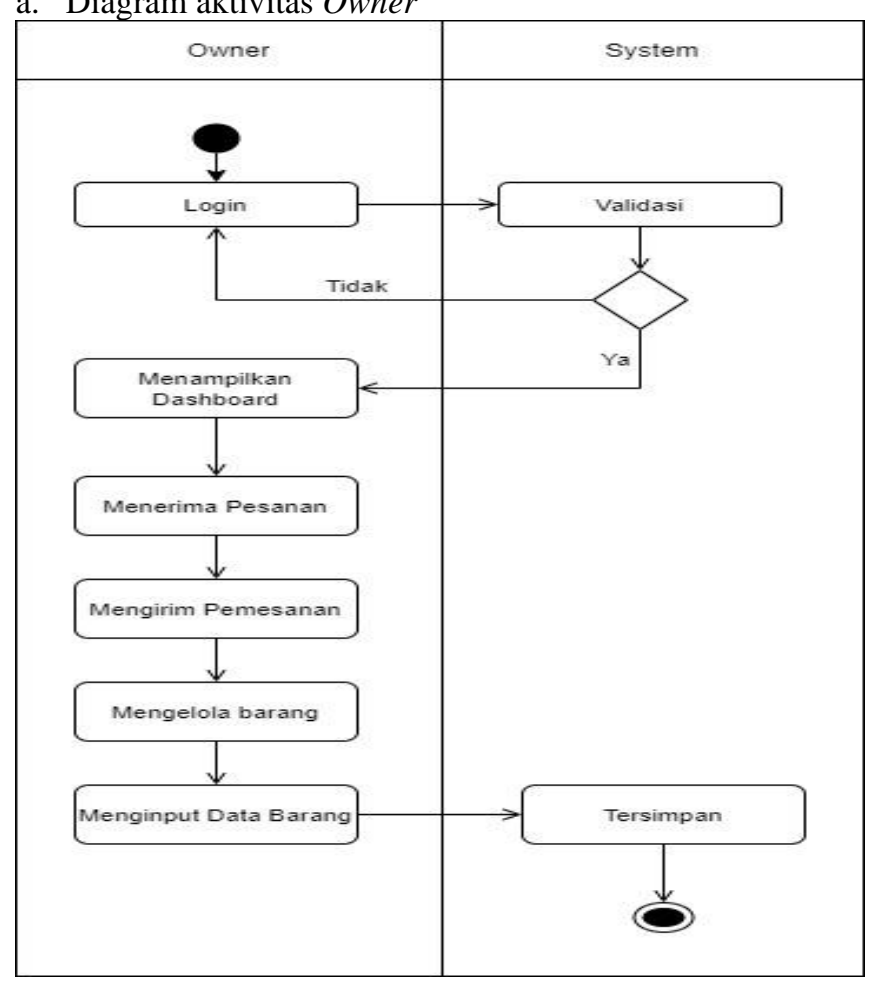

Gambar 2 Diagram Aktivitas Owner

Tabel IV.1 
b. Diagram aktivitas Karyawan

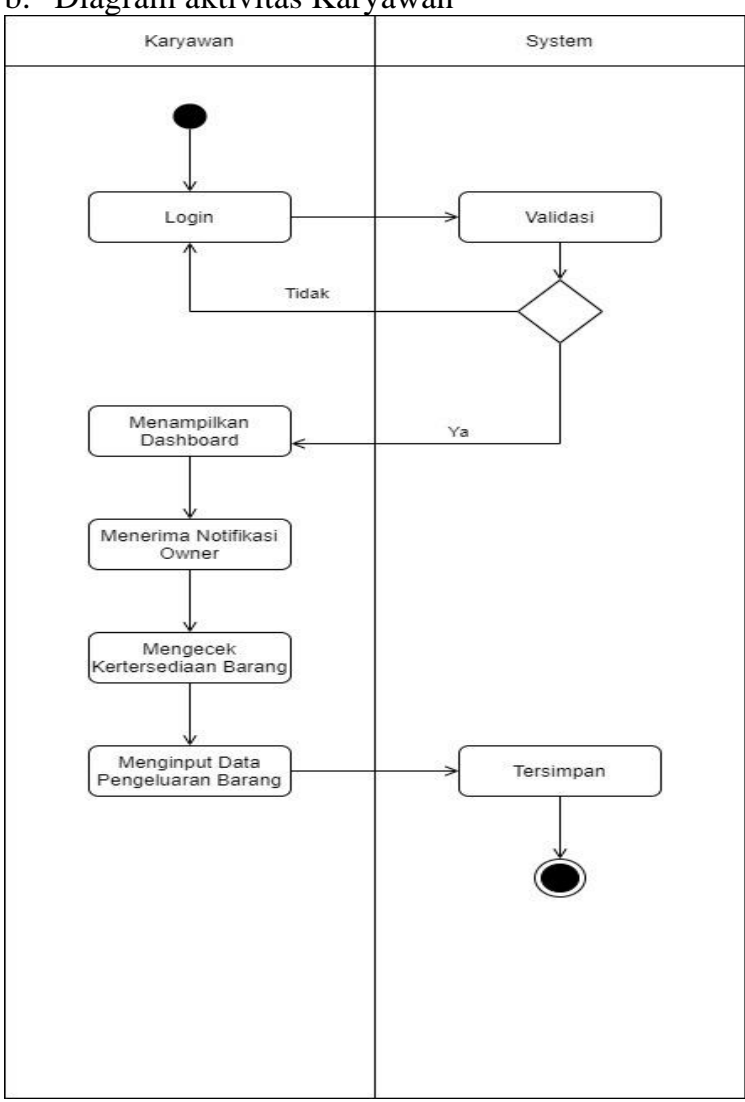

Gambar3.

Diagram Aktivitas Karyawan

\section{Rancangan Tampilan Aplikasi}

1. Tampilan menu login

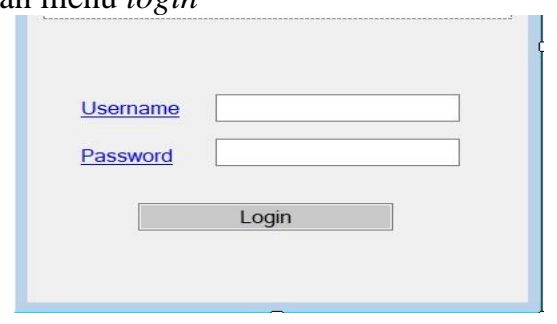

Gambar 4.Rancangan Login

2. Tampilan Menu Owner

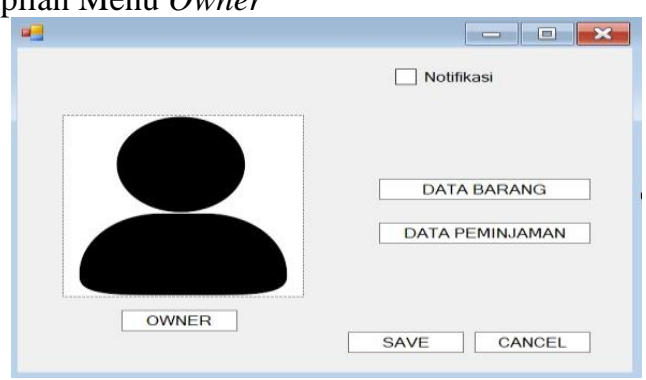

Gambar 5.Rancangan Menu Owner

3. Tampilan Menu Karyawan

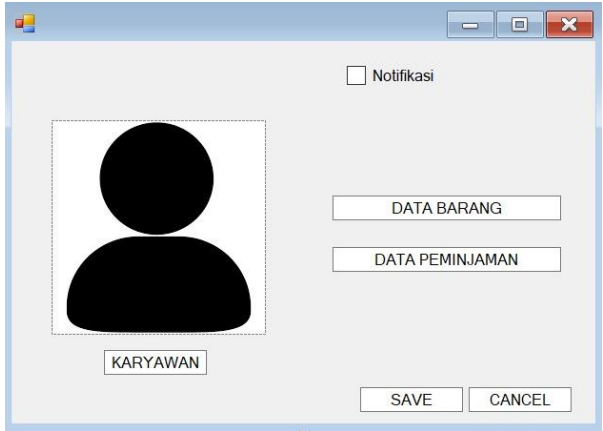

Gambar.6 Rancangan Prototype Menu Karyawan

4. Tampilan input peminjaman

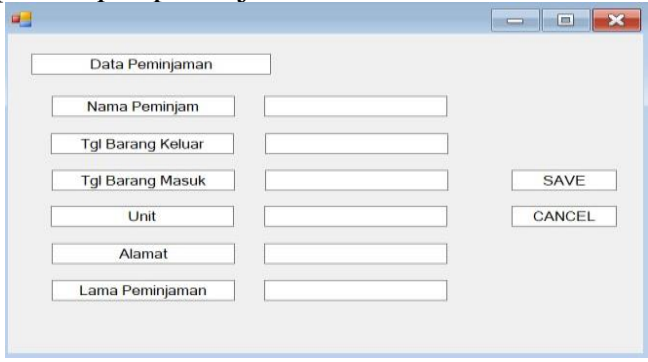

Gambar 7

Rancangan Input Peminjaman

5. Tampilan submit peminjaman

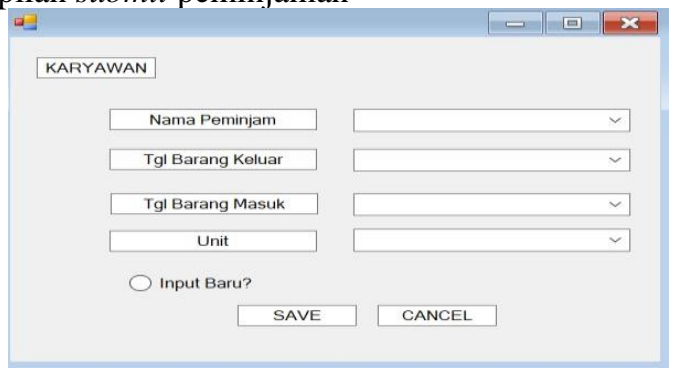

Gambar 8

Rancangan Submit Peminjaman

6. Tampilan menu tampilan owner

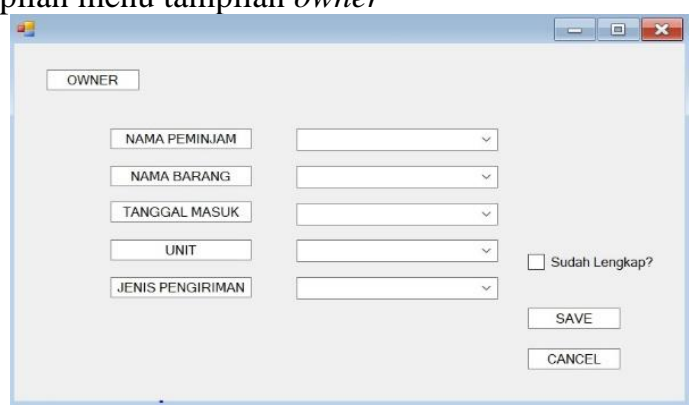

Gambar 9

Rancangan Menu Tampilan Owner 


\section{E. Perancangan Perangkat Lunak}

\section{a.Entity Relationship Diagram ( ERD )}

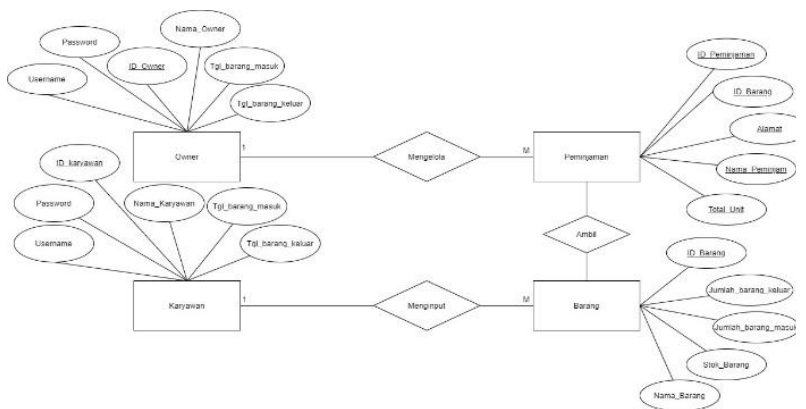

Gambar 10 Entity Relationship Diagram ( ERD )

\section{b.Logical Record Structural ( LRS )}

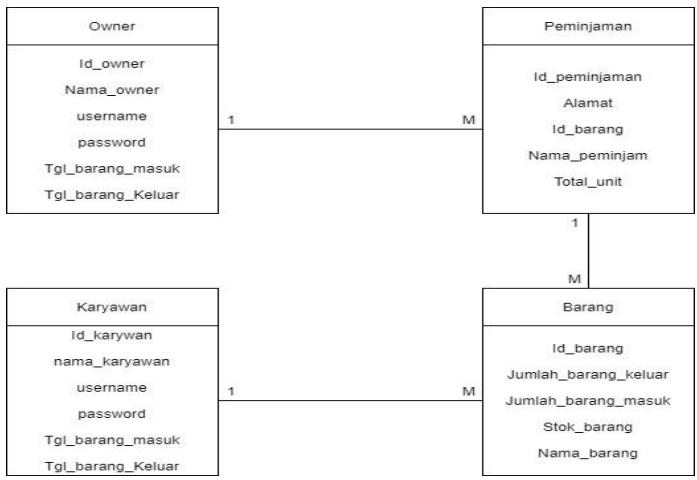

Gambar 11 Logical Record Structural ( LRS )

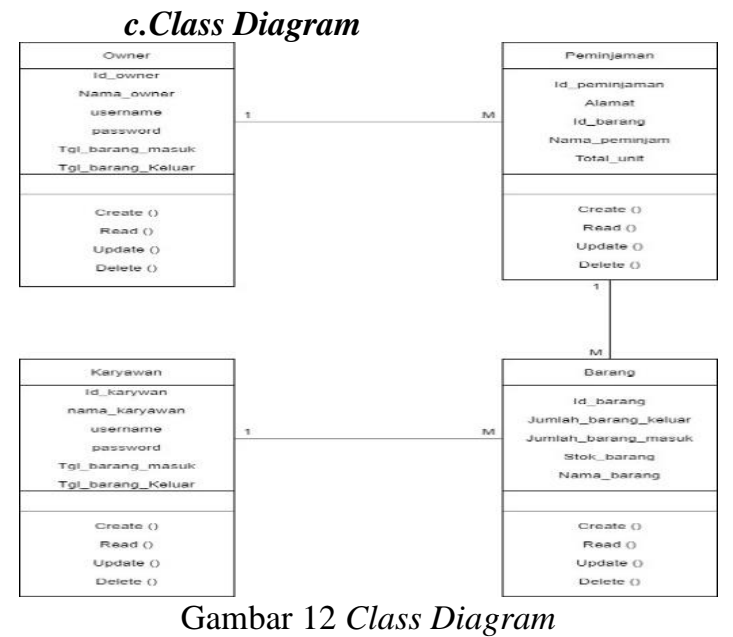

\section{d.Sequence Diagram}

1. Sequence Diagram Owner



Gambar I3. Sequence Diagram Owner

2. Sequence Diagram Karyawan

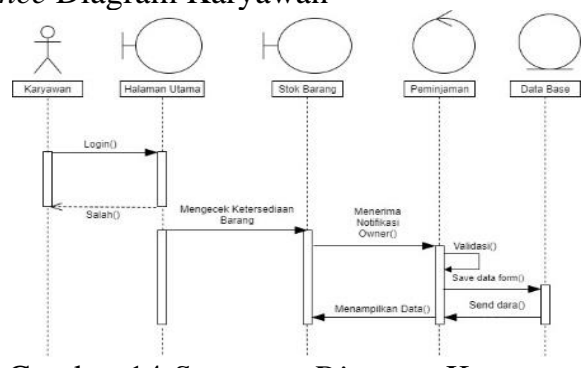

Gambar 14 Sequence Diagram Karyawan

\section{F. Pengujian sistem}

Pengujian dilakukan menggunakan blackbox testing

Tabel 1. Hasil Pengujian Login

\begin{tabular}{|l|l|l|l|l|}
\hline No. & $\begin{array}{l}\text { Scenario } \\
\text { pengujian }\end{array}$ & $\begin{array}{l}\text { Hasil } \\
\text { diharapkan }\end{array}$ & $\begin{array}{l}\text { Hasil } \\
\text { Pengujian }\end{array}$ & Kesimpulan \\
\hline 1 & $\begin{array}{l}\text { Mengosongkan } \\
\text { semua data } \\
\text { inputan }\end{array}$ & $\begin{array}{l}\text { Menampilkan } \\
\text { pesan data } \\
\text { harus di isi }\end{array}$ & $\begin{array}{l}\text { Sesuai } \\
\text { harapan }\end{array}$ & Valid \\
\hline 2 & $\begin{array}{l}\text { Mengisi } \\
\text { Username atau } \\
\text { Password } \\
\text { salah, lalu klik } \\
\text { tombol masuk }\end{array}$ & $\begin{array}{l}\text { Menampilkan } \\
\text { pesan } \\
\text { username } \\
\text { atau } \\
\text { password } \\
\text { salah }\end{array}$ & $\begin{array}{l}\text { Sesuai } \\
\text { harapan }\end{array}$ & Valid \\
\hline 3 & $\begin{array}{l}\text { Mengisi } \\
\text { Username atau } \\
\text { Password } \\
\text { benar, lalu klik } \\
\text { tombol masuk }\end{array}$ & $\begin{array}{l}\text { Masuk } \\
\text { halaman } \\
\text { aplikasi }\end{array}$ & $\begin{array}{l}\text { Sesuai } \\
\text { harapan }\end{array}$ & Valid \\
\hline
\end{tabular}

Tabel 2. Hasil Pengujian input peminjaman

\begin{tabular}{|l|l|l|l|l|}
\hline No. & $\begin{array}{l}\text { Scenario } \\
\text { pengujian }\end{array}$ & $\begin{array}{l}\text { Hasil } \\
\text { diharapkan }\end{array}$ & $\begin{array}{l}\text { Hasil } \\
\text { Pengujian }\end{array}$ & Kesimpulan \\
\hline 1 & $\begin{array}{l}\text { Mengosongkan } \\
\text { semua data } \\
\text { inputan }\end{array}$ & $\begin{array}{l}\text { Menampilkan } \\
\text { pesan data } \\
\text { harus di isi }\end{array}$ & $\begin{array}{l}\text { Sesuai } \\
\text { harapan }\end{array}$ & Valid \\
\hline 2 & $\begin{array}{l}\text { Mengisi } \\
\text { sebagian data }\end{array}$ & $\begin{array}{l}\text { Menampilkan } \\
\text { pesan data } \\
\text { belum } \\
\text { lengkap terisi }\end{array}$ & $\begin{array}{l}\text { Sesuai } \\
\text { harapan }\end{array}$ & Valid \\
\hline 3 & $\begin{array}{l}\text { Mengisi semua } \\
\text { data dan } \\
\text { lengkap }\end{array}$ & $\begin{array}{l}\text { Menampilkan } \\
\text { pesan data } \\
\text { sudah } \\
\text { tersimpan }\end{array}$ & $\begin{array}{l}\text { Sesuai } \\
\text { harapan }\end{array}$ & Valid \\
\hline
\end{tabular}




\section{KESIMPULAN}

Berdasarkan penelitian yang dilakukan dengan adanya aplikasi dalam proses peminjan akan memberikan perbaikkan system. Proses input data pada aplikasi akan tersimpan dengan baik pada database sehingga data tidak mudah hilang. Dengan adanya aplikasi peminjaman yang dirancang menggunakan metode perancangan agile proses pembuatan aplikasi melalui tahap Analisa kebutuhan sehingga akan menyesuaikan dengan kondisi yang dibutuhkan oleh perusahaan maupun pengguna aplikasi untuk memberikan kebutuhan.

\section{REFERENSI}

Anam, K. (2018). Analisa Dan Perancangan Sistem Informasi Akademik Berbasis Web Pada Mi Al-Mursyidiyyah Al-'Asyirotussyafi'Iyyah. Jurnal Teknik Informatika, 11(2), 207-217.

Andani, E. S., Informatika, M., \& Sumbawa, U. T. (2019). SISTEM INFORMASI ADMINISTRASI AKADEMIK PADA BIMBINGAN BELAJAR BERBASIS WEB ( STUDI KASUS DILA SAMAWA ) Dosen Informatika, Universitas Teknologi Sumbawa Rodianto@uts.ac.id ,, 2 Evasapitri751@gmail.com Abstrak. 1(1), 110.

Ferdiyanto, Y. A. (2019). Perancangan Sistem Informasi Pemerintahan Berbasis Web Studi Kasus Kantor Kelurahan Sumur Batu. Paradigma - Jurnal Komputer Dan Informatika, 21(1), 113-116.

Firmansyah. (2020). Sistem Informasi Pengaduan Warga Berbasis Website ( Studi Kasus: Kelurahan Siantan Tengah , Pontianak Utara ). Jurnal Cendikia, XIX(April), 397-404.

Handa Gustiawan. (2019). SISTEM INFORMASI KEARSIPAN PADA PT. PERMATA GRAHA NUSANTARA (PGNMAS). A $\gamma \alpha \eta, 8(5), 55$.

Heriyanto, Y. (2018). Perancangan Sistem Informasi Rental Mobil Berbasis Web Pada PT.APM Rent Car. Jurnal Intra-Tech, 2(2), 64-77.

Khasbi, I., Nugraha, F., \& Muzid, S. (2016). Sistem Informasi Peminjaman Ruang dan Barang di Universitas Muria Kudus Berbasis Web Menggunakan Fitur AMA Nitification. Jurnal SIMETRIS, Vol 7(No 2), 513-520

Ibnu Dwi Lesmono. (2018). Sistem Informasi Penjualan Merchandise Berbasis Web Pada PT Come Indonusa Dengan Metode Waterfall. 6(2), 91-97.

Latest, W., Information, M., \& Version, E. (2018). istem Informasi Pemesanan Paket Pariwisata Berbasis Web Pada Smart Tour Purwokerto. 4(06), 50-53.

Lidiawati. (2018). ANALISIS DAN PERANCANGAN SISTEM INFORMASI REKAM MEDIS PASIEN UMUM PADA KLINIK ART
MEDIKA. 6(1).

Listiyoko, L., Fahrudin, A., \& Maksum, A. (2017). Perancangan Aplikasi Cafe Untuk Efisiensi Order. Seminar Nasional Teknologi Informasi, 113-120.

Mubarok, A., Purnomo, E., \& Noor, C. M. (2019). Pengembangan Aplikasi Pembayaran Sumbangan Pengembangan Pendidikan Berbasis Web. Journal of Chemical Information and Modeling, 53(9), 1689-1699.

Romadhon, S. S., Studi, P., \& Informatika, T. (2019). Vol . 3 No . 1 Februari 2019 ISSN : 2597-3673 ( Online ) ISSN : 2579-5201 ( Printed ) ISSN : 2597-3673 ( Online ) ISSN: 2579-5201 ( Printed ). PERANCANGAN WEBSITE SISTEM INFORMASI SIMPAN PINJAM MENGGUNAKAN FRAMEWORK CODEIGINTER PADA KOPERASI BUMI ISSN : 2579-5201 (Printed) PERANCANGAN SEJAHTERA JAKARTA Syahrul, 3(1), 21-28.

Saputera, S. A., \& Yunita, E. (2019). JSAI, Volume 2 Nomor 2 , Juni 2019 Desain Sistem Edutaiment Berbasis Web di Sekolah Menengah Atas ISSN : 2614-3062; E-ISSN : 2614-3054. 2, 177-184.

Septiani, M., Afni, N., \& Andharsaputri, R. L. (2019). Perancangan Sistem Informasi Penyewaan Alat Berat. JUSIM (Jurnal Sistem Informasi Musirawas), 4(02), 127-135.

Tone, K. (2016). RANCANG BANGUN SISTEM INFORMASI DISTRIBUSI BANTUAN SOSIAL. Jurnal Instek Volume 1.Nomor 1. ISSN 2541-1179, 1- 10 